\title{
Results make a monkey of OPV-AIDS theory
}

Although they may question when and how, most scientists accept that human immunodeficiency virus (HIV)-1 came from simian immunodeficiency virus (SIV) carried in the chimpanzee subspecies Pan troglodytes troglodytes from west central Africa. Now, results of PCR analyses presented to a packed auditorium at London's Royal Society on 12 September should clarify the 'how' by dispelling one proposed route of transmission-that HIV-1 entered the human population inadvertently in the late 1950s through trials of an oral polio vaccine (OPV) grown in chimpanzee kidney cells contaminated with SIV.

The more conventional belief is that the virus jumped species through the hunting and handling of chimpanzeesthe 'natural transfer' or 'cut hunter' theory-and was propagated by urbanization and increased geographic mobility. The OPV theory of AIDS is founded on the temporal association between the earliest AIDS cases (1960s) and the oldest tissue sample of HIV-blood taken from a man in Kinshasa in the Democratic Republic of Congo in 1959-and trials of a vaccine for polio being carried out in the region around the same time by a team from the Wistar Institute in Philadelphia.

First printed in Rolling Stone magazine in 1992, the OPV theory has been championed with renewed vigor by former journalist Ed Hooper, who last year published a book on the subject, The River: A Journey Back to the Source of HIV and AIDS (Nature Med. 5, 1117; 1999). Hooper's friendship with fellow OPV theory proponent and member of the Royal Society, the late Bill Hamilton (Nature M ed. 6, 367; 2000), resulted in the society meeting to debate the means by which HIV became a human pandemic.

The two-day conference was oversubscribed, and a testament to the seriousness of the debate was reflected in the number of 'heavyweight' scientists who had flown in especially from the US: John Moore, professor of microbiology and immunology, Cornell University; Dennis Burton, professor of immunolgy, Scripps Research Institute; Neal Nathanson, retiring director of the
Office of AIDS Research at the National Institutes of Health; Vanessa Hirsh of the National Institute of Allergy and Infectious Diseases; Steve Wolinsky, professor of medicine at Northwestern University, Chicago; and Jon Allan, of the Southwest Foundation for Biomedical Research in Texas.

Hooper maintains that the polio vaccine tested on around one million Africans in the Congo was prepared using chimp kidneys contaminated with SIV from animals kept at a research facility close to Stanleyville (present-day Kisangani), a fact denied by team leaders Hilary Koprowski and Stanley

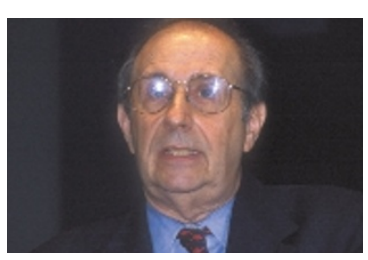

Stanley Plotkin sist, but also manufactured locally in the Congo using chimp tissue.

In turn, Plotkin announced that he has affidavits from 16 individuals who worked on the project that no chimp tissue was used and that no vaccine was produced locally. The meeting degenerated with Hooper accusing Plotkin of having coerced people into signing prepared written statements. One man, claims Hooper, was suffering from Alzheimer disease when he signed. Plotkin announced that he and his colleagues were being called "liars." He called for an end to discussion of the "fantasy" hypothesis and asked for a return to tack-

Plotkin. Last year, to coincide with his book release, Hooper renewed calls for remaining samples of CHAT 13-the vaccine lot pinpointed in The River as the suspect batch-to be analyzed for presence of HIV/SIV.

Consequently, this summer, three international laboratories-Shirley Kwock's group at Roche Molecular Systems in California, Svante Paabo's team at the Max Planck Institute in Germany and Simon Wain-Hobson's collaborators at the Pasteur Institute in France-tested samples in 'blinded' studies at an

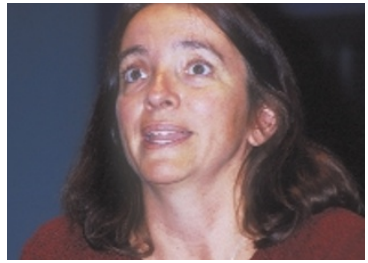

Bette Korber ling HIV through, what else, the development of a vaccine.

Amid the méleé, other world expertsin their field presented evidence to contradict the OPV theory. Kevin de Cock of the Centers for Disease Control and Prevention based in Nairobi explained that, even allowing for poor reporting of AIDS in disparate villages with limited health care surveillance mechanisms, a causal link with vaccination would mean that several thousand cases of the disease would have existed by the early 1960s. This was not the case.

Bette Korber of the Los to the Wistar Institute. None of the samples showed the presence of SIV or HIV, nor did they contain chimpanzee mitochondrial DNA, but indicated

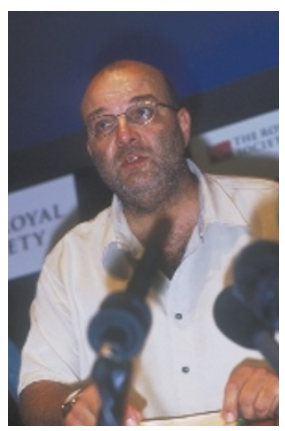
Ed Hooper instead that the vaccine derived from these samples had been grown in monkey substrate-macaque kidney cells to be precise.

But Hooper is undeterred. He dismissed the results as having no relevance to the OPV theory, and now argues that the samples tested were from a different batch than that responsible for the infection. He also insisted that he has uncovered new 'evidence'. He says he has taped statements from laboratory workers that vaccine was not just prepared in the US and shipped back for trials, as Koprowski and team in-
Alamos National Laboratory presented phylogenetic data that sets the date of the common ancestor of HIV-1-which could be either human or simian-between 1915 and 1941 (Science 289, 1140; 2000). She reaffirmed this time point with new data from samples collected from the Congo, and was supported by Ann-Mieke Vandamme from the Rega Institute for Medical Research in Belgium, who also amazed the audience with new predictions that SIV can be traced back to 1675 .

Such early origins mean that at least nine genetically distinct viruses would have had to have entered the human population simultaneously through the vaccine to correspond to the clade-rich phylogenetic tree at the 1959 time point-an event that most scientists deem implausible, but that Hooper believes entirely possible.

Karen Birmingham, London 